\title{
Solvation Studies on Sodium Dodecyl Sulphate in aqueous solutions at different temperatures
}

\author{
A. Gomathiyalini, K. Renuka Devi*, S. Rathika and S. Geetha \\ Govt Arts College for Women (Autonomous), Pudukkottai, Tamil Nadu, India - 622001.
}

\begin{abstract}
The solution behaviour of sodium dodecyl sulphate have been investigated by measuring velocity, density and viscosity at different temperatures in the range $308^{\circ} \mathrm{K}-323^{\circ} \mathrm{K}$ at an interval of $5^{\circ} \mathrm{K}$. The interaction between ion and water molecules can be described using hydration number values for aqueous solutions of electrolyte. Adiabatic compressibility, apparent molal volume and apparent molal compressibility for the above electrolyte SDS are determined using the theoretical formulations. Using the assumption that compressibility of the solution is mainly due to the contribution of free solvent molecules, a new methodology for finding the hydration number has been developed by Kalyanasundaram et al. Based on that method, hydration number for sodium dodecyl sulphate is calculated. From the calculated values of hydration number, molar solvated volume is determined using different formulae and found to be in agreement.
\end{abstract}

Keywords: SDS, solvation, ultrasonic velocity, adiabatic compressibility, hydration number, molar solvated volume.

\section{Introduction}

Sodium dodecyl sulphate chosen for present investigation is an anionic surfactant. SDS can be grouped into the electrolyte because it contains both a negative hydrophilic group (anion $\mathrm{SO}_{3}{ }^{-}$) and positive alkyl chain. Various thermodynamical parameters of SDS have been already calculated in previous papers. But this is a first attempt to evaluate the solvation properties and to study the salvation effects of SDS in aqueous solutions.

Due to the inadequate knowledge about the water structure, the molecular nature of ion- water interaction is known completely. The interaction of ion with water is described in terms of ion-hydration. The number of solvent molecules bound to single ion is termed as solvation (or) hydration number. Using the molar hydration number $\mathrm{n}_{\mathrm{h}}$ and molal hydration number $\mathrm{n}_{\mathrm{h}}$ ' values, the molar solvated volume, apparent molal volume and apparent molal compressibility have been evaluated for the electrolyte SDS at different concentrations and different temperatures.

\section{Experimental Study}

Aqueous solutions of different concentrations of SDS are prepared with Analar grade salt with double distilled water. Computations of the acoustical parameters require measurement of ultrasonic velocity, viscosity and density. A Mittal interferometer working at $2 \mathrm{MHz}$ frequency is used to find ultrasonic velocity of solutions with accuracy of $\pm 0.05 \%$. The density and viscosity of the solutions are measured using $10 \mathrm{ml}$ specific gravity bottle and Ostwald viscometer. The above measurements are carried out for the solutions at different temperatures from $308^{\circ} \mathrm{K}-323^{\circ} \mathrm{K}$. The experimental temperatures have been maintained by using a constant temperature bath.

\section{Calculation and Discussions}

Acoustical parameters such as molar hydration number $\left(\mathrm{n}_{\mathrm{h}}\right)$ and molal hydration number $\left(\mathrm{n}_{\mathrm{h}}{ }^{\prime}\right)$, molar solvated volume, apparent molal volume and apparent molal compressibility were calculated.

Adiabatic compressibility:

The adiabatic compressibility of the solution is found from the ultrasonic velocity and density values using the relation,

$$
\beta=\left(1 / \mathrm{U}^{2} \rho\right) \quad \mathrm{Kg}^{-1} \mathrm{~ms}^{2} \quad \text {---- (1) }
$$

The values of $\beta$ are represented in table- (1) which decreases linearly with respect to temperature, decreases with increase of concentration up to $0.008 \mathrm{~m}$ and attains maximum at $0.010 \mathrm{~m}$ then decreases linearly. The $\beta$ value decreases due to the breaking up of solvent molecules which increases the number of solute particles surrounding the solvent resulting in hydration effect.

\section{Apparent molal Volume:}

Kohlrausch and Hallwach's ${ }^{[1]}$ introduced symbol $\varphi_{\mathrm{v}}$ for the apparent molal volume. They showed experimentally that $\varphi_{v}$, is directly proportional to $\left(\rho-\rho_{0}\right) / C$ which is given by the following equation, 


$$
\varphi_{\mathrm{v}}=\left[1000\left(\rho-\rho_{0}\right) / \mathrm{n}_{2} \rho_{0}\right]+\mathrm{M}_{2} / \rho_{0} \mathrm{~m}^{3} \mathrm{~mole}^{-1}
$$

where, $\rho$ and $\rho_{0}$ be the density of solution and solvent respectively, $\mathrm{M}_{2}$ is the molecular weight of solute. The apparent molal volume values are calculated and tabulated in table-(1).

The apparent volume has been proven to be a very useful tool in elucidating the structural interactions occurring in the solution. When different salts are added to fixed volume of solvent, that volume gets decreased shown by Watson ${ }^{[2]}$. This result was checked by Holker ${ }^{[3]}$. That is the change in volume after adding the salt to solvent may be positive or negative depending upon the nature of salt, temperature and concentration. For SDS $\varphi_{\mathrm{V}}$ shows a non linear variation that may be either due to contraction in volume of solvent by adsorption of salt or by electrostriction. The negative value of $\varphi_{\mathrm{V}}$ at higher temperature $323^{\circ} \mathrm{K}$ indicates the presence of solutesolvent interactions.

\section{Hydration Number:}

The degree of hydration is measured by a quantity known as hydration number assigned to each individual ion. The hydration number can be defined as number of solvent molecules per ion, which remains attached to a given ion, long enough to experience its translation movement when solution is formed. The estimated values of hydration number available in literature as well as the definition of hydration itself vary depending on the different features of molecular process attributed by the investigators ${ }^{[4-5]}$. Solvation properties are also affected by the structure of surrounding molecule. Using the assumption that the compressibility of the solution is mainly due to the free solvent molecules, the methodology of computing salvation number has been recently reported ${ }^{[0-8]}$.

The molar hydration number $n_{h}$ is derived from the Passynski's ${ }^{[9]}$ relation given as follows,

$$
\mathrm{n}_{\mathrm{h}}=\left[\mathrm{n}_{1}-\beta \mathrm{N} / \beta_{0}\right] / \mathrm{n}_{2}
$$

where $\beta$ nd $\beta_{0}$ be the compressibility of solution and solvent respectively, $n_{1}$ is the number of moles of the solvent present in $1000 \mathrm{cc}$ of the solution of molar concentration $\mathrm{n}_{2}$ and $\mathrm{N}$ is the number of moles of the solvent in $1000 \mathrm{cc}$ of the solvent.

The molar hydration number can also be obtained using Barnatt's ${ }^{[10]}$ equation,

$$
\mathrm{n}_{\mathrm{h}}=\mathrm{n}_{1}\left(1-\mathrm{V} \beta / \mathrm{n}_{1} \mathrm{~V}_{1} \beta_{0}\right] / \mathrm{n}_{2}
$$

where $V_{1}$ is the molar volume of the solvent and $V=1000 \mathrm{cc}$.

The values of molar hydration number obtained from equations (3) and (4) are in good agreement and found to have non linear variation with respect to increase of temperature and concentration of solution represented in table - (1). This variation may be due to the hydration effect of hydrophilic and hydrophobic part of SDS over the solvent molecules which means the number of solute particles surrounding the solvent varies with concentration and temperature. The magnitude of molar hydration number is high and increases with increase of temperature, because more number of hydrophilic part of SDS is interacting with water molecules. The addition of ions to water causes a disruption or breakdown of the $\mathrm{H}_{2} \mathrm{O}$ structure. two relations,

Similarly, the molal hydration number $\mathrm{n}_{\mathrm{h}}$ ' given by Passynski has been computed using the following

and

$$
\begin{aligned}
& \mathrm{n}_{\mathrm{h}}{ }^{\prime}=\left[1-\beta / \beta_{0}\right] \mathrm{N}^{\prime} / \mathrm{n}_{2}{ }^{\prime} \\
& \mathrm{n}_{\mathrm{h}}{ }^{\prime}=\left[1-\beta / \beta_{0}\right] \mathrm{n}_{1} / \mathrm{n}_{2}
\end{aligned}
$$

where $\mathrm{N}^{\prime}$ is the number of moles of solvent in $1000 \mathrm{gm}$ of solvent and $\mathrm{n}_{2}{ }^{\prime}$ is the molal concentration of the solution.

The values of molal hydration number obtained from equations (5) and (6) are in agreement. The hydration number may be either positive or negative in relation with temperature and molality. In the present system, as the molality increases from lower value, the hydration number decreases and found to be positive. It increases with temperature rise upto $318^{\circ} \mathrm{K}$ and decreases at $323^{\circ} \mathrm{K}$ shown in table- (1).

This positive value in hydration number reveals the following facts.

(i) The compressibility of the solution will be less than that of solvent.

(ii) Solute molecules will gain mobility and have more probability of contacting solvent molecules. This may increase the interaction between solute and solvent molecules.

(iii) In the hydration sphere the solute-solvent interaction is more intensive than solvent-solvent molecules. 
Apparent molal compressibility:

Apparent molal compressibility $\varphi_{\mathrm{k}}$ of the solute is the compressibility of an amount of solution containing one mole of the solute minus the compressibility of the solvent. It is given by the relation,

$$
\varphi_{\mathrm{k}}=\left[1000\left(\rho_{0} \beta-\beta_{0} \rho\right) / \mathrm{n}_{2} \rho_{0}\right]+\mathrm{M}_{2} \beta_{0} / \rho_{0}
$$

The above equation is used to find the $\varphi_{\mathrm{k}}$ value in traditional method.

It may also be calculated using the following relations containing hydration number and apparent molal volume as follows,

and

$$
\begin{aligned}
& \varphi_{\mathrm{k}}=-\mathrm{V}_{1} \beta_{0} \mathrm{n}_{\mathrm{h}} \\
& \varphi_{\mathrm{k}}=\left(1000 / \mathrm{n}_{2}\right)\left(\beta-\beta_{0}\right)+\beta_{0} \varphi_{\mathrm{v}} \\
& \varphi_{\mathrm{k}}=-\mathrm{n}_{\mathrm{h}} \mathrm{V}_{1} \beta_{0}+\varphi_{\mathrm{v}} \beta
\end{aligned}
$$

The unit for $\varphi_{\mathrm{k}}$ is $\mathrm{ml} \mathrm{mole}^{-1} \mathrm{~m}^{2}$ dyne ${ }^{-1}$.The apparent molal compressibility values have been computed and compared and found to be the same in all equations from (7) to (10) and given in table-(2).

The $\varphi_{\mathrm{k}}$ shows a non linear variation with concentration as that of $\varphi_{\mathrm{v}} . \varphi_{\mathrm{k}}$ values of SDS solutions are negative at all temperatures and concentrations. This indicates ionic, dipolar interactions occurring in these solutions ${ }^{[11]}$. This is because at lower concentrations of SDS, the availability of water molecules are more, hence the chances for the penetration of SDS molecules are highly favoured. From the relations of $\varphi_{\mathrm{k}}$, it is clear that the variations in hydration number values are found to be reflected in the variations of apparent molal compressibility.

\section{Molar solvated volume:}

The molar solvated volume $\varphi_{\mathrm{s}}$ is computed using the following three relations,

and

$$
\begin{aligned}
& \varphi_{\mathrm{s}}=\mathrm{Vn}_{\mathrm{h}}{ }^{\prime} / \mathrm{n}_{1} \\
& \varphi_{\mathrm{s}}=\mathrm{V}_{1} \mathrm{n}_{\mathrm{h}}{ }^{\prime}\left(\beta / \beta_{0}\right)-\left(\mathrm{n}_{\mathrm{h}} \mathrm{V}_{1} \Delta \beta / \beta_{0}\right) \\
& \left.\varphi_{\mathrm{s}}=V \Delta \beta / \mathrm{n}_{2} \beta_{0}\right)
\end{aligned}
$$

The $\varphi_{\mathrm{s}}$ values calculated using the above equations (11) to (13) is found to be in good agreement which is shown in table- (2). The $\varphi_{s}$ values have the same variations as that of hydration number and apparent molal volume. It is observed that $\varphi_{s}$ values are dictated more by hydration number than by apparent molal volume.

\section{Conclusion}

Various solvation properties of electrolyte sodium dodecyl sulphate were evaluated at different temperatures and different concentrations. Adiabatic compressibility and apparent molal volume are computed for aqueous SDS. The values of molar and molal hydration numbers, apparent molal compressibility and molar solvated volume were computed from different theories available in literatures and found to be in good agreement.

From the investigation, it may be presumed that,

(i) The negative values of $\varphi_{\mathrm{k}}$ suggest that SDS is having strong structural breaking influence on the solvent.

(ii) Ion-dipolar/hydrophilic group interactions occurring between the ions of $\mathrm{SDS}\left(\mathrm{SO}_{3}^{-}, \mathrm{Na}^{+}\right.$, alkyl group) and $\left(\mathrm{OH}^{-}\right)$group of water.

(iii) Ion-hydrophilic group interactions taking place between the ions of SDS and polar parts of water.

[1]. Kohlrausch, F. and hallwachs, W., Ann. Phys. Chem., 5 (1894) 14.

[2]. Watson, R., Phil. Trans. Roy. Soc. London, 60 (1770) 325.

[3]. Holker, S., Phil. Magazine, 27 (1844) 207.

[4]. Hinton, J.F. and Amis, H.S., Chem. Rev., 71 (1971) 627.

[5]. Amis, E. and Hinton, J.F. Solvent effect on chemical phenomena, Academic press, pp.126-147 (1973).

[6]. Kalyanasundaram, S., and Saraswathi, S., J. Pure and Appl. Phys., 31 (1993) 869.

[7]. Sabesan, R., Kalyanasundaram, S., Saraswathi, S., and Premalatha S., J. Pure and Appl. ultrason., 16 (1994) 21.

[8]. Varadarajan R., Pia Thomas and Kalyanasundaram, S., J. Pure and Appl. ultrason., 17 (1995) 130.

[9]. Passynski, A., Acta. Physico. Chem., 8 (1930) 385.

[10]. Barnatt, S., Chem. Phys., 20 (1952) 278.

[11]. Thirumaran, S. and Mary Christina Gardilya, D., Recent research in Science and Technology, 3(8) (2011) 56-63. 
TABLE - 1

Adiabatic compressibility, apparent molal volume, molar and molal hydration numbers of aqueous SDS at different concentrations $(2 \mathrm{mM}$ to $14 \mathrm{mM})$ and at different temperatures $\left(308^{\circ} \mathrm{K}\right.$ to $\left.323^{\circ} \mathrm{K}\right)$

\begin{tabular}{|c|c|c|c|c|c|c|}
\hline \multirow{2}{*}{$\begin{array}{l}\text { Molality } \\
\text { (mole) }\end{array}$} & \multirow{2}{*}{$\begin{array}{c}\text { Adiabatic } \\
\text { Compressibility } \\
\left(10^{-10} \mathrm{Kg}^{-1} \mathrm{~ms}^{2}\right)\end{array}$} & \multirow{2}{*}{$\begin{array}{l}\text { Apparent molal volume } \\
\qquad\left(\mathrm{m}^{3} \mathrm{~mole}^{-1}\right)\end{array}$} & \multicolumn{2}{|c|}{ Molar Hydration number $\left(\mathrm{n}_{\mathrm{h}} * 10^{2}\right)$} & \multicolumn{2}{|c|}{ Molal Hydration number $\left(\mathrm{n}_{\mathrm{h}}{ }^{\prime}\right)$} \\
\hline & & & Eqn 3 & Eqn 4 & Eqn 5 & Eqn 6 \\
\hline \multicolumn{7}{|c|}{$308^{\circ} \mathrm{K}$} \\
\hline 0.002 & 4.3558 & 492.35 & 104.99 & 103.74 & 280.23 & 280.23 \\
\hline 0.004 & 4.3095 & 342.89 & 51.74 & 51.34 & 286.23 & 286.23 \\
\hline 0.006 & 4.2789 & 7.82 & 34.29 & 34.07 & 255.20 & 255.20 \\
\hline 0.008 & 4.2565 & 73.55 & 25.61 & 25.44 & 226.76 & 226.76 \\
\hline 0.010 & 4.3595 & 413.84 & 21.04 & 20.82 & 51.47 & 51.47 \\
\hline 0.012 & 4.2751 & 75.84 & 17.20 & 17.08 & 131.54 & 131.54 \\
\hline 0.014 & 4.2275 & 288.07 & 14.61 & 14.47 & 152.88 & 152.88 \\
\hline \multicolumn{7}{|c|}{$313^{\circ} \mathrm{K}$} \\
\hline 0.002 & 4.3212 & 833.34 & 104.72 & 103.69 & 224.00 & 224.00 \\
\hline 0.004 & 4.3073 & 149.06 & 52.27 & 51.82 & 152.69 & 152.69 \\
\hline 0.006 & 4.2666 & 92.27 & 34.54 & 34.25 & 190.64 & 190.64 \\
\hline 0.008 & 4.2322 & -23.52 & 25.73 & 25.53 & 195.91 & 195.91 \\
\hline 0.010 & 4.2932 & 272.65 & 20.92 & 20.70 & 80.44 & 80.44 \\
\hline 0.012 & 4.1862 & 118.47 & 17.01 & 16.85 & 180.67 & 180.67 \\
\hline 0.014 & 4.2182 & 244.26 & 14.72 & 14.55 & 124.73 & 124.73 \\
\hline \multicolumn{7}{|c|}{$318^{\circ} \mathrm{K}$} \\
\hline 0.002 & 4.3018 & 199.17 & 105.30 & 104.19 & 77.36 & 77.36 \\
\hline 0.004 & 4.2734 & 106.41 & 52.36 & 51.85 & 129.99 & 129.99 \\
\hline 0.006 & 4.2266 & 80.03 & 34.56 & 34.22 & 187.14 & 187.14 \\
\hline 0.008 & 4.1891 & 131.46 & 25.71 & 25.48 & 200.64 & 200.64 \\
\hline 0.010 & 4.2828 & 141.419 & 21.10 & 20.85 & 37.14 & 37.14 \\
\hline 0.012 & 4.1793 & 30.12 & 17.15 & 16.97 & 144.22 & 144.22 \\
\hline 0.014 & 4.1827 & 234.819 & 14.74 & 14.54 & 119.58 & 119.58 \\
\hline \multicolumn{7}{|c|}{$323^{\circ} \mathrm{K}$} \\
\hline 0.002 & 4.2875 & 42.89 & 105.13 & 103.80 & 121.83 & 121.83 \\
\hline 0.004 & 4.2590 & -202.49 & 52.27 & 51.66 & 152.88 & 152.88 \\
\hline 0.006 & 4.2103 & -228.51 & 34.48 & 34.10 & 206.57 & 206.57 \\
\hline 0.008 & 4.1846 & -217.60 & 25.73 & 25.46 & 196.26 & 196.26 \\
\hline 0.010 & 4.2487 & 7.56 & 20.95 & 20.69 & 73.00 & 73.00 \\
\hline 0.012 & 4.1278 & -73.42 & 16.97 & 16.78 & 189.56 & 189.56 \\
\hline 0.014 & 4.1066 & 122.506 & 14.48 & 14.28 & 183.95 & 183.95 \\
\hline
\end{tabular}


TABLE - 2

Apparent molal compressibility and molar solvated volume of aqueous SDS at different concentrations $(2 \mathrm{mM}$ to $14 \mathrm{mM})$ and at different temperatures $\left(308^{\circ} \mathrm{K}\right.$ to $\left.323^{\circ} \mathrm{K}\right)$

\begin{tabular}{|c|c|c|c|c|c|c|c|}
\hline \multirow[t]{2}{*}{$\begin{array}{l}\text { Molality } \\
\text { (mole) }\end{array}$} & \multicolumn{4}{|c|}{$\begin{array}{l}\text { Apparent molal compressibility } \\
\left(\varphi_{\mathrm{k}} * 10^{-7} \mathrm{ml} \mathrm{mole}^{-1} \mathrm{~m}^{2} \mathrm{dyne}^{-1}\right)\end{array}$} & \multicolumn{3}{|c|}{$\begin{array}{l}\text { Molar solvated volume } \\
\qquad\left(\varphi_{\mathrm{s}} * 10^{-3} \mathrm{~m}^{3} \mathrm{~mole}^{-1}\right)\end{array}$} \\
\hline & Eqn 7 & Eqn 8 & Eqn 9 & Eqn 10 & Eqn 11 & Eqn 12 & Eqn 13 \\
\hline \multicolumn{8}{|c|}{$308^{\circ} \mathrm{K}$} \\
\hline 0.002 & -2.00 & -2.23 & -2.00 & -2.02 & 100.99 & 100.99 & 100.99 \\
\hline 0.004 & -2.11 & -2.28 & -2.11 & -2.13 & 103.13 & 103.13 & 103.13 \\
\hline 0.006 & -2.01 & -2.03 & -2.01 & -2.03 & 91.95 & 91.95 & 91.95 \\
\hline 0.008 & -1.76 & -1.80 & -1.76 & -1.77 & 81.70 & 81.70 & 81.70 \\
\hline 0.010 & -0.22 & -0.41 & -0.22 & -0.23 & 18.54 & 18.54 & 18.54 \\
\hline 0.012 & -1.00 & -1.04 & -1.00 & -1.01 & 47.39 & 47.39 & 47.39 \\
\hline 0.014 & -1.08 & -1.21 & -1.08 & -1.10 & 55.08 & 55.08 & 55.08 \\
\hline \multicolumn{8}{|c|}{$313^{\circ} \mathrm{K}$} \\
\hline 0.002 & -1.39 & -1.42 & -1.39 & -1.41 & 80.71 & 80.71 & 80.71 \\
\hline 0.004 & -1.13 & -1.20 & -1.13 & -1.14 & 55.01 & 55.01 & 55.01 \\
\hline 0.006 & -1.45 & -1.50 & -1.45 & -1.46 & 68.69 & 68.69 & 68.69 \\
\hline 0.008 & -1.54 & -1.54 & -1.54 & -1.55 & 70.59 & 70.59 & 70.59 \\
\hline 0.010 & -0.51 & -0.63 & -0.51 & -0.52 & 28.98 & 28.98 & 28.98 \\
\hline 0.012 & -1.36 & -1.42 & -1.36 & -1.36 & 65.10 & 65.10 & 65.10 \\
\hline 0.014 & -0.87 & -0.89 & -0.87 & -0.87 & 44.94 & 44.94 & 44.94 \\
\hline \multicolumn{8}{|c|}{$318^{\circ} \mathrm{K}$} \\
\hline 0.002 & -0.51 & -0.60 & -0.51 & -0.52 & 27.87 & 27.87 & 27.87 \\
\hline 0.004 & -1.05 & -1.02 & -1.05 & -1.06 & 46.83 & 46.83 & 46.83 \\
\hline 0.006 & -1.48 & -1.46 & -1.48 & -1.50 & 67.43 & 67.43 & 67.43 \\
\hline 0.008 & -1.61 & -1.57 & -1.61 & -1.62 & 72.29 & 72.29 & 72.29 \\
\hline 0.010 & -0.22 & -0.28 & -0.22 & -0.23 & 13.38 & 13.38 & 13.38 \\
\hline 0.012 & -1.10 & -1.13 & -1.10 & -1.11 & 51.96 & 51.96 & 51.96 \\
\hline 0.014 & -0.82 & -0.86 & -0.82 & -0.84 & 43.08 & 43.08 & 43.08 \\
\hline \multicolumn{8}{|c|}{$323^{\circ} \mathrm{K}$} \\
\hline 0.002 & -0.92 & -0.92 & -0.92 & -0.93 & 43.90 & 43.90 & 43.90 \\
\hline 0.004 & -1.27 & -1.25 & -1.27 & -1.28 & 55.08 & 55.08 & 55.08 \\
\hline 0.006 & -1.70 & -1.69 & -1.70 & -1.71 & 74.43 & 74.43 & 74.43 \\
\hline 0.008 & -1.61 & -1.59 & -1.61 & -1.62 & 70.71 & 70.71 & 70.71 \\
\hline 0.010 & -0.56 & -0.56 & -0.56 & -0.57 & 26.30 & 26.30 & 26.30 \\
\hline 0.012 & -1.50 & -1.48 & -1.50 & -1.51 & 68.30 & 68.30 & 68.30 \\
\hline 0.014 & -1.37 & -1.41 & -1.37 & -1.39 & 66.28 & 66.28 & 66.28 \\
\hline
\end{tabular}

